\title{
RELATORIO RELATIVO AO ANNO LECTIVO DE 1926
}

Cumprindo o disposto na letra $i$ do art. 144 do Decreto 11530, de 1915, letra $f$ do art. 199 do Decr. 16872 A, de 13 de janeiro de 1925 e n. XVIII do art. $90^{\circ}$ do antigo Regimento Interno desta Faculdade e do n. XVI do art. 8. do actual Regimento, passo a fazer o relatorio minucioso de tudo quanto occorreu, neste estabelecimento, a respeito da disciplina, ordem, serviço militar, e observancia das leis e do orçamento, no anno lectivo de 1926.

DIRECTORIA - Em sessão extraordinaria da Congregação dos professores, especialmente convocada e, realizada no dia 13 de janeiro, o Dr. Uladislau Herculano de Freitas, de saudosa memoria, então Director desta Faculdade, communicou deixar, nesse dia o exercicio desse cargo, por ter de ir tomar posse do cargo de Ministro do Supremo Tribunal Federal, para o qual fôra nomeado por decr. de 7 de dezembro de 1925, passando, por isso, a Directoria ao Dr. Antonio Amancio Pereira de Carvalho, na qualidade de vice-Director, por ser o professor mais antigo.

O Dr. Antonio Januario Pinto Ferraz, professor cathedratico em disponibilidade, nomeado Director, por decreto de 19 de maio, tomou posse desse cargo no dia 24 de julho, tendo entrado em exercicio no dia 2 de agosto.

ABERTURA DOS TABALHOS - Na fórma do disposto nos arts. 74 do decreto 11530 , de 1915 e 202 do decr. 16782-A, de 1925 e 143 do Regimento Interno, en- 
tão em vigor, os trabalhos deste instituto de ensino foram abertos no 'dia 2 de março, celebrando a Congregação dos proifessores a sua primeira reunião.

PRESENÇA DE PROFESSORES - Na primeira reunião da Congregação, realizada a 2 de março, foi verificado que se achavam promptos para o serviço os professores - Antonio Januario Pinto Ferraz, Manoęl Pedro Villaboim, José de Alcantara Machado d'Oliveira, Candido Nazianzeno Nogueira da Motta, Frederico Vergueiro Steidel, João Braz de Oliveira Arruda, Luiz Barbosa da Gama Cerqueira, Estevam de Araujo Almeida, Manoel Pacheco Prates, Theophiloj Benedicto de Souza Carvalho, José Joaquim Cardozo de Mello Neto, Francisco Antonio de Almeida Morato, Raphael Corrêa de Sampaio, José Augusto Cesar, Spencer Vampré e Braz de Sousa Arruda.

EXAME VESTIBULAR - $\mathrm{Na}$ forma do disposto no art. 62 do Regimento Interno, em vigor, a inscripção para o exame vestibular, instituido pelo dec. 11530, de 1915, e do art. 202 do dec. 16782-A, de 1925, para a matricula no curso desta Faculdade, aberta a 3 de janeiro e encerrada a 31 , ex-vi do telegramma de 11 desse mesmo mez, ldo Dr. Director Geral do Departamento Nacional do Ensino, concorreram 102 candidatos. O exame iniciou-se, com a prova escripta, no dia 16 de março, terminando no dia 6 de abril, tendo sido approvados 101 candidatos não tendo um feito a prova escripta. (Annexo II).

A commissão julgadora desse exame foi constituida pelos professores Drs. Manoel Pacheco Prates, Theophilo Benedicto de Souza Carvalho e Spencer Vampré, tendo sido a mesa presidida pelo professor mais antigo, em exercicio, Dr. Antonio Januario Pinto Ferraz, na falta do vice-Director, que exercia o cargo de Director.

HORARIO DAS AULAS - Pelo Dr. Director interino, foi adoptado, na forma do disposto na letra $k$ ) do 
art. 199 do citado dec. 16782-A, de 1925, foi adoptado o horario das aulas, constante do Annexo I.

PROGRAMMAS DE ENSINO - Adoptados pelos professores das cadeiras do curso, foi nomeada uma commissão composta dos Drs. Luiz Barbosa da Gama Cerqueira, José Joaquim Cardozo de Mello Neto e José Augusto Cesar, a qual formulou o seu parecer, opinando pela sua approvação pela Congregação, em sessão de $\bar{\zeta}$ de março, tendo pela mesma Congregação, por proposta dos Drs. Theophilo Benedicto de Souza Carvalho, José Joaquim Cardozo de Mello Neto e Waldemar Martins Ferreira, que approvada, adoptado para o anno lectivo de 1926, o mesmo programma de Direito Constitucional, que fôra approvado para o anno lectivo de 1925, visto que estava vaga a cadeira dessa disciplina. Os programmas foram impressos a postos á venda na Thesouraria da Faculdade.

DESIGNAÇÃO DE PROFESSORES - No correr do anno lectivo findo, foram designados: o Bacharel Waldemar Martins Ferreira, livre docente, para reger a $1 .^{a}$ cadeira do $3 .^{\circ}$ anno, em substituirgão ao Dr. Octavio Mendes e, depois, em substituição ao Dr. Frederico Vergueiro Steidel e a $1 .^{a}$ cadeira do $4 .^{\circ}$ anno, em substituição ao mesmo Dr. Octavio Mendes; o Bacharel Antonio de Sampaio Doria, livre docente, para reger a $1 .^{a}$ cadeira do $1 .^{\circ}$ anno, que vagou com a disponibilidade ido Dr. Uladislau Herculano de Freitas; o Bacharel José Rodrigues de Rezende Filho, livre docente, para reger a $4 .^{a}$ cadeira do $4 .^{\circ}$ anno, que vagou com o fallecimento do Dr. Estevam de Araujo Almeida; o Dr. Raphael Corrêa de Sampaio, cathedratico, para reger a $2 .^{\text {a }}$ cadeira ido $5 .^{\circ}$ anno, que estava vaga com a aposentadoria do Dr. José Manoel de Azevedo Marques a $3 .^{a}$ cadeira do $5 .^{\circ}$ anno, em substituição ao Dr. José de Alcantara Machado d'Oliveira, e a $2 .^{\text {a }}$ cadeira do $3 .^{\circ}$ anno, em substituição ao Dr. Luiz 
Barbosa da Gama Cerqueina; o Dr. Manoel Pacheco Prates, cathedratico para reger a $3 .^{\mathrm{a}}$ cadeira do $4 .^{\circ}$ anno, que vagou com a disponibilidade do Dr. Antonio Januario Pinto Ferraz, e a $3 .^{a}$ cadeira do $3 .^{\circ}$ anno, eu substituição ao Dr. José Augusto Cesar; e o Dr. Theophilo Benedicto ide Souza Carvalho, cathedratico, para reger a $4 .^{\text {a }}$ cadeira do 5. anno, em substituição ao Dr. Manoel Pedro Villaboim.

INSCRIPÇÃO PAARA EXAMES DA SEGUNDA EPOCA - Para os exames da $2 .^{\text {a }}$ epoca, inscreveram-se 72 alumnos, sendo: no $1 .^{\circ}$ anno, 11 , no $2 .^{\circ}-16$, no $3 .^{\circ}-11$, no $4 .^{\circ}-32$, e no $5 .^{\circ}-2$. O resultado desses exames consta do Annexo II.

INSCRIPÇÃO DE MATRICULA - Matricularamse nos cinco annos do curso 375 alumnos, sendo: no $1 .^{\circ}$ anno 109 , no $2 .^{\circ}-75$, no $3 .^{\circ} 459$, no 4 . $^{-}-72$, e, no $5 .^{\circ}-60$.

TRANSFERENCIA DE MATRICULA - Durante 0 periodo das ferias, somente cinco alumnos requereram guia de transferencia, sendo: 2 do $1 .^{\circ}$ anno, 2 do 2 . para a Faculdade de Direito da Universidade do Rio de Janeiro e 1. da $3 .^{\circ}$ anno, para a Faculdade de Direito do Recife.

LICENÇAS - Durante o anno findo, estiveram de licença: o Dr. Frederico Vergueiro Steidel, cathedratico da $1 .^{\text {a }}$ cadeira do $3 .^{\circ}$ anno, de 10 de maio a 22 de agosto; tendo fallecido no dia 26 de agosto; o Dr. Luiz Barbosa da Gama Cerqueira, cathedratico da 2. ${ }^{a}$ cadeira do 3 . $^{\circ}$ anno, de 10 de abril a 9 de março; เo Dr. José Augusto Cesar, cathedratico da $3 .^{\text {a }}$ cadeira do 3 . anno, de 9 de abril a 2 de julho; o Dr. Octavio Mendes, cathedratico da $1 .{ }^{\text {. }}$ cadeira do $4 .^{\circ}$ anno, de $10^{\circ}$ de janeiro a $1 .^{\circ}$ de outubro; e o Dr. Estevam de Araujo Almeida, cathedratico da 4." cadeira do 4. anno, de 12 a 17 de abril, tendo fallecido no dia 18.

SERVIÇO PUBLICO - Durante o anno fíndo, estiveram ausentes da Faculdade; por motivo de serviço 
publico: o Dr. Manoel Pedro Villaboim, cathedratico da $4 .^{a}$ cadeira do $5 .^{\circ}$ anno, de 4 de maio a 31 de dezembro, por estar com assento no Congresso Nacional, como Deputado pelo Estado de São Paulo; o Dr. Reynaldo Porchat, cathedratico em disponibilidade, como representante desta Faculdade no Conselho do Ensino Secundario e Superior, de 21 de setembro a $1 .^{\circ}$ de novembro; e o Dr. José d'e Alcantara Machado d'Oliveira, cathedratico da $3 .^{a}$ cadeira do $5 .^{\circ}$ anno, por estar em commissão do Ministerio da Justiça e Negocios Interiores, de $1 .^{\circ}$ de agosto a 31 de dezembro.

SUBSTITUIÇÕES - No correr do anno findo, o Dr. Antonio Amancio Pereira de Carvalho, cathedratico mais antigo, em disponibilidade, e, então vice-Director, na forma da lei, substituiu ao Dr. Uladislau Herculano de Freitas, no exercicio do cargo de Director, de 14 de jameiro a 1. de agosto; o bacharel Waldemar Martins Ferreira, livre docente de Direito Commercial, de $1 .^{\circ}$ de janeiro a $1 .^{\circ}$ de outubro, regeu a $1 .^{a}$ cadeira do $4 .^{\circ}$ anno, em substituição ao Dr. Octavio Mendes, que esteve no gozo de licença, e, de 10 de maio a 31 de dezembro, regeu a $1 .^{2}$ cadieira do $3 .^{\circ}$ anno, em substituição ao Dr. Frederico Vergueiro Steidel, que esteve no gozo de licença e depois falleceu; o Bacharel Antonio de Sampaio Doria, livre docente de Direito Publico e Constitucional e de Direito Internacional Publico e Privado, de $10^{\circ}$ de abril a 31 de dezembro, regeu a $1 .^{\mathrm{a}}$ cadeira do $1 .^{\circ}$ anno, em substituição ao Dr. Uladislau Herculano die Freitas, que foi posto em disponibilidade; o Bacharel Gabriel José Rodrigues de Rezende Filho, livre docente de Theoria e Pratica do Processó Civil e Commercial, de 12 de abril a 31 de dezembro, regeu a $4 .^{a}$ cadeira do $4 .^{\circ}$ anno, que estava vaga, em substituição ao Dr. Estevam de Araujo Almeida, que falleceu; o Dr. Raphael Corrêa de Sampaio, cathedratico, de $1 .^{\circ}$ de janeiro a 31 de dezembro, regeu a $2 .^{a} \mathrm{ca}$ - 
deira do $5 .^{\circ}$ anno, que estava vaga, em substituição ao Dr. José Manoel de Azevedo Marques, que fôra aposentado, de 10 de abril a 19 de maio, tambem regeu a $2 .^{a}$ cadeira do $3 .^{\circ}$ anno, em substituição ao'Dr. Luiz Barbosa da Gama Cerqueira, que estevie no gozo de licença, e, de 3 de agosto a 31 de dezembro tambem regeu a $3 .^{a}$ cadeira do 5. ${ }^{\circ}$ anno, em substituição ao Dr. José de Alcantara Machado d'Oliveira, que esteve em Commissão 'do Ministerio da Justiça e Negocios Interiores; o Dr. Manoel Pacheco Prates, cathedratico, de $10^{\circ}$ de abril a' 31 de dezembro, regeu a $3 .^{\circ}$ cadeira da $4 .^{\circ}$ anno, que estava vaga, em substituição o Dr. Antonio Januario Pinto Ferraz, que foi posto em disponibilidadie, e, de 12 de abril a 2 de julho, tambem regeu a $3 .^{\mathrm{a}}$ cadeira do 3 . anno, em substituição ao Dr. José Augusto Cesar, que esteve no gozo de licença; e o Dr. Theophilo Benedicto de Souza Carvalho, cathedratico, de 4 'de maio a 31 de dezembro, regeu a $4.0^{\text {al }}$ cadleira do 5. ${ }^{\circ}$ anno, em substituição ao Dr. Manoel Pedro Villaboim, que estevè com assento no Congresso Nacional, como Deputada pelo Estado de São Paulo.

REPRESENTAÇÃO NO DEPARTAMENTO NACIONAL DO ENSINO — Para representar esta Faculdade no Conselin do Ensino Secundario Superior, junto ao Departamento Nacional do Ensino, no anno findo, foi eleito o cathedratico, em disponibilidade, Dr. Reynaldo Porchat, na sessão da Congregação realizada a 2 de março.

COMMISSÕES AUXILIARES DO DIRECTOR $\mathrm{Na}$ sessão da Congregação realizada a 2 de março, foram eleitos os cathedraticos Drs. João Braz de Oliveira Arrúdia, José Joaquim Cardozo de Mẹllo Neto e Spencer Vampré, para a commissão de ensino; Antonio Januario Pinto Ferraz, Manoel Pedro Villaboim a Theophil'o Benedicto de Souza Carvalho, para a commissão de docencia; e Manoel Pacheco Prates, Francisco Antonio de Almeida 
Morato e Braz de Sousa Arruda, para a commissão de redaç̧ão de publicações.

DISPONIBILIDADE DE PROFESSORES - No correr do anno findo, entraram no gozo das vantagens da disponibilidade, que lhes fôra concedida, no dia $1 .^{\circ} \mathrm{de}$ janeiro, o Dr. Uladislau Herculano de Freitas, cathedratico de Direito Publico e Constitucional, que a obteve por dec. de 29 de agosto de 1925 e no dia 31 de março, o Dr. Antonio Januario Pinto Ferraz, cathedratico de uma das cadeiras de Direito Civil, que a obteve por dec. de 29 , de julho de 1925.

FALLECIMENTOS - No correr do anno findo, falleceram: O Dr. Estevam de Araujo Almeida, cathedratico, no exercicio da $4 .^{2}$ cadeira do $4 .{ }^{\prime}$ anno, no dia 18 de abril e o Dr. Frederico Vergueiro Steidel, cathedratico, no exer-

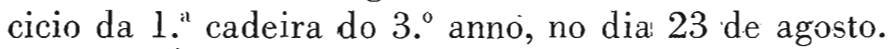

VAGAS DE CADEIRAS - Com a disponibilidade do Dr. Uladislau Herculano de Freitas, cathedratico de Direito Publico e Constitucional, (hoje Direito Constitucional), ficou vaga essa cadeira, no dia $1 .^{\circ}$ de janeiro; com a disponibilidade do Dr. Antonio Pereira de Carvalho, cathedratico de Medicina Publica (3. ${ }^{a}$ cadeira do 5. anno), (hoje $1 .^{a}$ cadeira do $4 .^{\circ}$ anno), ficou vaga essa cadeira, no dia 14 de janeiro; com a disponibilidade do Dr. Antonio Januario Pinto Ferraz, cathedratico de Direito Civil, então em exercicio da $3 .^{a}$ cadeira do $4 .^{\alpha}$ anno (hoje $1 .^{a}$ cadeira do $3 .^{\circ}$ anno), ficou vaga essa cadeira, no dia $1 .^{\circ}$ de abril; no dia 31 de março, com o fallecimento do Dr. Estevam de Araujo Almeida, cathedratico de Theoria do Processo Civil e Commercial, $4 .^{a}$ cadeira do $4 .^{\circ}$ anno, hoje fundida com a cadeira de Pratica do Processo Civil e Commercial, (1. ${ }^{a}$ cadeira do $5 .^{\circ}$ anno), com a de Direito $\mathrm{Ju}^{-}$ diciario (3. ${ }^{a}$ cadeira do 4 . anno, Theoria e Pratica do Processo Civil e Commercial) ficou vaga essa całdeira, no dia 
18 de abril e com o fallecimento do Dr. Frederico Vergueiro Steidel, cathedratico de Direito Commercial, com exercicio na $1 .^{a}$ cadeira do $3 .^{\circ}$ anno (hoje $2 .^{a}$ cadeira do $2 .^{\circ}$ anno, Parte geral, Sociedades e Contractos), ficou vaga essa cadeira, no dia 23 de agosto.

NOMEAÇÃO E POSSE DO DIRECTOR - O Dr. Antonio Januario Pinto Ferraz, cathedratico em disponi-bilidade, nomeado Director desta Faculdade, por decreto de maio, tomou posse no dia 24 de julho, tendo entrado em exercicio desse cargo no idia 2 de agosto.

DEFESA DE THESES - A defesa de theses do Ba charel Raul Apocalypse, designada para o dia 29 de março e adiada, a requerimento do candidato para o dia 5 de abril, não se realizou, por não ter o referido candidato comparecido.

INSCRIPÇÃO PARA HABILITAÇÃO DE DIPLOMADO ESTRÁNGEIRO - No dia 19 de agosto o Snr. Antonio Ruffolo, diplomado em Jurisprudencia pela Real Universidade de Roma, requereu a sua habilitação para o exercicio da profissão no Brasil. 'Autorizada a inscripção, foi esta feita, com a apresentação dos documentos exigidos, nos termos do disposto nos arts. 61 e 62 do dec. 16782-A, de 1925, citado, tendo sido designado o mez de março de 1927, para a realização do exame, em dia que fosse previamente annunciado.

DOCENCIA LIVRE - Na fórma do disposto no artigo 179 do citado dec. 16782-A, de 1925, annunciadit e encerrada a inscripção para a docencia livre, a ella concorrerám to Dr. José dos Passos da Silva Cunha, para a cadeira de Medicina Publica; os Bachareis Raul Renato Cardoso de Mello Tocunduva, para a de Direito Judiciario Civil; Octavio Moreira Guimarães, e Jorge Americano, para 
a de Direito Civil do $3 .^{\circ}$ anno (Obrigações), Edgard Vieira Cardoso para a de Direito Publico Internacional e Renato de Andradie Maia para a de Direito Commercial, 2. ${ }^{\mathrm{a}}$ cadeira do $2 .^{\circ}$ anno (Parte Geral, Sociedades e Contractos). A Congregação dos Professores, em sessão realizada a 16 de outubro, tomando conhecimento dessas inscrip̧̧ões para o concurso da docencia livre, resolveu, mediante parecer da respectiva commissão de docencia, o qual foi approvado, que fossem indeferidos: o requerimento do Dr. José dos Passos da Silva Cunha, por ser maior de 40 annos; o do Bacharel Octavio Moreira Guimarães, por ter mais dd 40 annos e tambem ter requerido a docencia livre sómente para Direito das Obrigações; o do Bacharel Jorge Americano, por ter requerido o docencia livre sómente de uma parte de Direito Civil (Direito 'das Obrigações) e o do Bacharel Renato de Andrade Maia, por ter requerido a docencia livre somente da Parte Geral, Socie. dades e Contractos, no direito Commercial e que fossem deferidos apenas os requerimentos do Bacharel Raul Renato Cardoso de Mello Tocunduva, para a docencia livre de Direito Judiciario Civil e do Bacharel Edgard Vieira Cardoso, para a docencia livre de Direito Publico Internacional. Nessa mesma reunião da Congregação, de 16 de outubro, procedeu-se a eleição dos membros que tinham de compor as commissões examinadoras nos concursos para a docencia livre, sendo então eleitos para a de Direito Judiciario Civil, os Drs. João Braz de Oliveira Arruda, Raphael Corrêa de Sampaio e Manoel Pacheco Prates, alem do professor dd cadeira, Dr. Francisco Antonio de Almeida Morato, que, nos termos do disposto no art. 165 ido dec. 16782 $\leadsto$, era membro effectivo dessa commissão, e para supplentes, no caso d'e falta occasional, os professores Drs. José Ulpiano Pinto de Souza, em disponibilidade e Spencer Vampré, e para a de Direito Publico Internacional, os Drs Raphael Corrêa de Sampaio, Theophilo Benedicto de Souza Car- 
ralho e Jcisé JJoaquim 'Cardozo de Mello Neto, alem do professor da cardeira Dr. Braz de Sousa Arruda, que, nos termos do art. 165 do dec. 16782-A, era membro effectivo dessa commlissão. Designados os dias 27 de outubro, para o inicio do concurso para a docencia livre de Direito Judiciario Civil, e 28 do mesmo mez para a dos de Direito Publico Internacional, nenhuma dessas provas se realizou, visto terem os respectivos candidatos della diesistidio.

CONCURSOS PARA PROFESSORES CATHEDRATICOS - Conforme editaes publicados foram aber. tas e encerradas, pelo prazo de' seis mezes, as inscripçõez para o preenchimenta dos logares vagos de professor cathedratico de Direito Constitucional, Direito Civil e Direito Commercial; as das duas primeiras disciplinas, foram abertas a 17 de abril e encerradas a 18 de outubro, tendo sidla a de Direito Commercial aberta a 1. de dezembro. A's inscripções para a cadeira de Direito Constitucional, concorreram quatro candidatos, Bachareis Antonio de Sampaio Dioria, Ernesto de Moraes Leme, Ary de Azevedo Fonseca e Hermes Lima; e ás de Direito Civil, concorreram seis candidatos - Bacháreis Jorge Americano, Vicente Ráo, Antonio Marques dols Reis, Aureliano Candido de Oliveira Guimarães, Lino de Moraes Leme 'e Carlos de Moraes Andrade. Submettidos á Congregação os requerimentos da inscripção de cada um desses candidatos, approvou ella as inscripções dos Bachareis Antonio de Sampaio Doria e Hermes Lima, em Direito Constitucional, e Jorge Americano, Vicente Ráo e Aureliano Candido de Olivelira Guimarães em Direito Civil, julgando não habilitados os demais candlidatos, por não terem satisfeito todos ołs requisitos exigidos pela legislaçãol em vigor, resolvendo a mesma Congregação que as provas dio Concurso de Direito Constitucional se realizassem, em novembro do anno findo e as de Direito Civil, em abril de 1927. As 
provas do concurso para o preenchimento do logar de pro. fessor cathedratico de Direito Constitucional, a que se submetteram os dois umicos candidatos julgados legalmente inscriptos e aptos para esse concurso, tiveram inicio no dia 18 de dezembro e terminaram no dia 23 desse memo mez, dia em que, em sessão publica, se realizou o julgamento, que deu o resultado seguinte: Bacharel Antonio de Sampaio Doria, com a media final de nove e vinte e dois centesimos $(9,22$ cs.) e Bacharel Hermes Lima, com a media de seis e quarenta et sete centesimos $(6,47$ cs.), tendo sido, na sessão da Congregação dos Professores de 28 de dezembro finda, assignado o 'officio de communicação ao Governo nome do Bacharel Antonio de Sampaio Doria candidato habilitado no mesmo concurso para o provimento do logar de professor cathedratico de Direito Constitucional.

INSCRIPÇÃO PARA EXAMES DA PRIMEIRA EPOCA - Para os exames da $1 .^{a}$ epoca, inscreveram-se 321 alumnos, senido: no $1 .^{\alpha}$ anno, 99 , no $2 .^{\circ}-64$, no $3 .^{\circ}-43$, no $4 .^{\circ}-58$ e no $5 .^{\circ}-57$ : O resultado deșses exames consta do Annexo II.

COLLAÇÃO DE GRAU - Durante o anno findo, foi collado o grau de Bacharel em Sciencias Juridicas e Sociaes a 67 bacharelandos, os quaes são naturaes dos seguintes Estad'os: São Paulo-40, Minas Geraes -5, Rio de Janreiro-2, Amazonas-1, Matto Grosso-1, Cidaide do Rio de Janeiro-1, 'do Reino da Italia-1 e da Republica Argientina:1, constantes do Annexo III.

CARTAS DE BACHAREL - No correr do anno findo, foram expedidas 67 Cartas de Bacharel a igual numero de Bachareis formad'os por esta Faculdade em Sciencias Juridicas e Sociaes, os quaes são naturaes dos se- 
guintes Estados: São Paulo-49, Minas Geraes-7; Rio de Janeiro-3, Rio Grande do Sul-2, Matto Grosso-1, Amazonas1, Bahia-1; da Cidade do Rio de Janeiro-1, do Reino da Italia-l e da Republica Argentina-1.

SERVIÇO MILITAR - Até a presente data não fơi ainda apresentado pelo respectivo instructor o resultado dos exames do serviço militar prestados pelos alumnos desta Faculdade, que o frequentarem durante o anno findo.

SESSẼES DA CONGREGAÇÃO - No correr do anno findo, a Congregação dos professores celebrou quatorze sessões, tendo sido uma extraordinaria.

PROCEDIMENTO DOS ALUMNOS - $\mathrm{O}$ procedimento dos alumnos no correr d'o anno find do, foi bom, não tendo occorrido coisa alguma digna de menção.

BIBLIOTHECA - A Bibliotheca desta Faculdade, durante o anno findo, foi frequentada por 4962 pessôas, que consultaram 2055 obras em 3090 volumes, sendo: em portuguez-1221, francez-360, latim-10, italiano-106, inglez-60 e hespanhol-4; e, 2025 consulentes, que leram jornaes e revistas. Annexo V.

Os empregados da Bibliotheca bem cumpriram os seus deveres.

THESOURARIA - O Balanço da Thesouraria desta Faculdade, constante do Annexo IV, e fechado a 5 de janeiro finido, accusa que da Receita e Despeza ha um saldo de 692:264\$900 (seiscentos' e noventa e d'ois contos duzentos e sessenta e quatro mil novecentos réis), assim distribuido: No Banco do Brasil-2:174\$700 (dois contos cento e setenta e quatro mil setecentos réis), no Banco do Commercio e Industria-4:090\$200 (quatro contos e noventa mil duzentos réis) e 686:000\$000 (seliscentos e oitenta e seis contos de réis) importancia de 686 apolices da União do valor de 1:000\$000 cada uma, ao juro de $5 \%$ ao anno. 
O saldlo apurado em 1925, foi de 727:212 $\$ 400$ (setecentos e vinte sete contos duzentos e doze mil e quatrocentos réis), havendo, portanto, uma differença a menos de 34:947\$500 (trinta e quatro contos novecentos e quarenta e sete mil quinhentos réis).

O Thesoureiro bem cumpriu os seus deveres.

SECRETARIA - Os serviços da Secretaria estiveram sempre em dia tendo os empregados bem cumprido os seus deveres.

Secretaria da Faculdade de Direito de São Paulo, em 23 de Fevereiro de 1927.

O Director:

Antonio Januario Pinto Ferraz.

NOTA: os Annexos citados, estão archivados na Secretaria da Faculdade. 